\title{
Penerapan Pembelajaran Konstruktivis-Novick dengan Media Edutainment terhadap Motivasi dan Pemahaman Konsep Siswa
}

\section{Application of Constructivis-Novick Learning with Media Edutainment on Motivation and Understanding of Student Concept}

\author{
Ashari Najib'), Muhammad Ali P.1), Nurhidayah' ${ }^{2 * *}$ \\ ${ }^{1}$ Program Studi Pendidikan Matematika, Universitas Al Asyariah Mandar \\ ${ }^{2}$ Program Studi Pendidikan Matematika, Universitas Sulawesi Barat
}

Received $28^{\text {th }}$ August 2019 / Accepted 24 ${ }^{\text {th }}$ September 2019

\begin{abstract}
ABSTRAK
Penelitian ini bertujuan untuk mengetahui pengaruh penerapan model konstruktivis novick dengan media edutainment terhadap motivasi dan pemahaman konsep siswa. adapun populasi dalam penelitian ini yaitu siswa kelas X MIPA SMA Negeri 1 Wonomulyo sebanyak 180 siswa yang terbagi kedalam 5 kelas, kemudian diambil sampel dengan menggunakan teknik simple random sampling sebanyak 2 kelas yaitu kelas $X$ MIPA 1 sebagai kelas eksperimen dan X MIPA 3 sebagai kelas kontrol. instrumen yang digunakan dalam penelitian ini yaitu tes pemahaman konsep siswa dan angket motivasi belajar siswa. Hasil penelitian yang diperoleh yaitu (1) motivasi belajar matematika siswa yang diajar dengan menggunakan model pembelajaran konstruktivis novick lebih tinggi dibandingkan motivasi belajar siswa yang diajar tanpa model pembelajaran konstruktivis novick dengan media edutainment, dan (2) rata-rata pamahaman konsep siswa yang diajar dengan menggunakan model pembelajaran konstruktivis novick dengan media edutainment lebih besar dibandingkan rata-rata pemahaman konsep siswa yang diajar tanpa menggunakan model pembelajaran konstruktivis novick dengan media edutainment.
\end{abstract}

Kata Kunci: Konstruktivis Novick, Edutainment, Motivasi, Pemahaman Konsep

\begin{abstract}
The research aims to determine the influence of the application of the Constructivis Novick model with the media edutainment towards the motivation and understanding of the student concept. As for the population in this research is the grade X students MIPA SMA Negeri 1 Wonomulyo as many as 180 students are divided into 5 classes, then taken samples using simple random sampling technique as many as 2 classes: $X$ class MIPA 1 as Class Experimental and X MIPA 3 as the control class. The instrument used in this study is a test of understanding the concept of students and the learning Motivation
\end{abstract}

*Korespondensi:

email: nurhidayah.inung19@gmail.com 
questionnaire for students. The results of the research obtained is (1) The motivation to learn mathematics students who are taught using the Novick's Constructivicist learning model is higher than the learning motivation of students taught without the model of constructivicist Novick Learning With the media edutainment, and (2) the average concept of students taught by using a model of constructivical learning Novick with the media edutainment greater than the average understanding of the concept of students taught without using the model Novick's constructivicist learning with the media edutainment.

Keywords: Constructivis Novick, Edutainment, Motivasi, Concept Comprehension

\section{PENDAHULUAN}

Mengingat melalui model pembelajaran guru dapat membantu siswa mendapatkan informasi, ide, keterampilan, cara berpikir, dan mengekspresikan ide, oleh karena itu dalam proses pembelajaran matematika diperlukan suatu model pembelajaran yang bervariasi untuk mengatasi berbagai permasalahan di atas terutama dalam hal meningkatkan motivasi belajardan hasil belajar. Selain itu, pelaksaaan pembelajaran yang dapat meningkatkan motivasi siswa dalam belajar juga sangat diperlukan, sebab tanpa motivasi yang dimiliki oleh siswa maka materi pembelajaran akan sulit dipahami oleh siswa. Salah satu pembelajaran yang memungkinkan siswa dapat mengkonstruksi pengetahuan dan terlibat secara aktif dalam pembelajaran adalah dengan memadukan antara model pembelajaran konstruktivis novick dengan media edutainment.

Pembelajaran berbasis konstruktivisme merupakan pembelajaran yang menuntut siswa aktif membangun sendiri pengetahuannya, mencari arti yang dipelajari, membuat penalaran dengan menemukan makna, membandingkan pengetahuan yang telah diketahui dengan pengetahuan yang baru, dan menyesuaikan konsep yang baru dipelajari dengan pemahaman awal (Rahmawati dkk, 2015).

Pembelajaran konstruktivis tipe novick merupakan model pembelajaran yang mampu(1) menghadirkan suatu fenomena tertentu yang daat membangun pemahaman siswa mengenai konsep yang diajarkan, (2) menumbuhkan kemampuan berpikir siswa untuk meningkatkan pengetahuan dalam rangka memecahkan masalah kehidupan seharihari, dan (3) menciptakan alternatif pembelajaran konstruktivis.Hal ini disebabkan karena dalam fase pembelajaran merangsang peningkatan pemahaman konsep siswa (Masruroh dkk, 2014).Hasil penelitian yang dilakukan Sulaiman (2013) menunjukkan bahwa penerapan pembelajaran dengan model pembelajaran konstruktivis novick efektif dalam meningkatkan motivasi dan hasil belajar siswa.

Adapun tahapan-tahapan model pembelajaran konstruktivis novick menurut Prayitno \& Sugiharto (2017) yaitu : 
Tabel 1. Tahapan-tahapan Model Pembelajaran Konstruktivis Novick

\begin{tabular}{ll}
\hline \multicolumn{1}{c}{ FASE-FASE } & \multicolumn{1}{c}{ PERILAKU GURU } \\
\hline Fase 1 & Guru menggali konsep awal yang berkaitan dengan materi yang \\
Exposing & akan diajarkan. \\
alternative & Langkah yang dapat dilakukan yaitu dengan (1) menghadirkan \\
framework & fenomena dan meminta siswa menelaah fenomena tersebut, \\
& meminta siswa menjelaskan fenomena yang telah diketahui dan \\
& meminta siswa meramalkan mengenai fenomena yang belum \\
& diketahui, (2) menugaskan siswa mendeskripsikan konsepsinya \\
& dalam bentuk uraian, gambaran ilustrasi, peta konsep, dan lain- \\
& lain. \\
\hline Fase 2 & Guru menciptakan konflik konseptual berdasarkan konsepsi siswa. \\
Creating & Langkah ini dilakukan dengan mengarahkan siswa berdiskusi \\
Conceptual & dalam kelompok, membimbing siswa untuk demontrasi atau \\
conflict & eksperimen yang hasilnya dapat membantah konsep yang tidak \\
& ilmiah yang dimiliki siswa. \\
\hline Fase 3 & Guru mendorong terlaksananya akomodasi kognitif untuk struktur \\
Encouraging & kognitif siswa. \\
cognitive & Guru menyediakan pengalaman belajar dengan melakukan \\
acomidation & percobaan untuk lebih meyakinkan siwa bahwa konsepsinya tidak \\
& benar. Guru perlu mengajukan pertanyaan yang sifatnya menggali \\
& konsepsi siswa \\
\hline
\end{tabular}

Istilah media berasal dari bahasa Latin yang berarti bentuk jamak dari "medium" yang secara harafiah merupakan perantara atau pengantar. Jadi dapat dikatakan bahwa media merupakan perantara atau pengantar pesan dari pengirim kepada penerima pesan (Sadiman dalam Triyanto dkk, 2013).

Menurut Heinich media merupakan alat saluran komunikasi.Sedangkan menurut Scrham media pembelajaran merupakan teknologi pembawa pesan yang dapat dimanfaatkan untuk keperluan pembelajaran.Media selalu terdiri dari 2 unsur penting yakni unsur peralatan dan unsur pesan yang dibawanya.Media memerlukan peralatan untuk menyajikan pesan, namun yang terpenting bukanlah peralatan tersebut, tetapi pesan atau informasi belajar yang dibawakan oleh media tersebut (Susilana \& Riyana, 2009).

Edutaiment merupakan gabungan dari edukasi dan entertaiment.Edutaiment merupakan desain pembelajaran yang memadukan antara muatan pendidikan dengan dan hiburan secara harmonis, sehingga dengan perpaduan ini mencipatakan pembelajaran yang menyenangkan (Andani \& Herawati, 2013).Edutainment sebagai pembelajaran dikemas secara menarik dan menyenangkan melalui kegiatan, media, ataupun bahan ajar dengan tetap memperhatikan tujuan pembelajaran yang ingin dicapai.Melalui kegiatan pembelajaran yang bernuansa hiburan diharapkan siswa dapat melakukan kegiatan 
pembelajaran tanpa tekanan, sehingga dapat memberikan kenyamanan serta menumbuhkan motivasi belajar siswa (Ardianti dkk, 2017).

Buckingham dan Scanlon menyatakan bahwa edutaiment merupakan perpaduan kategori- kategori yang menitiberatkan pada materi visual, narasi, permainan dan gaya pengajaran yang informal, tujuannya adalah agar dapat menarik perhatian siswa melalui komputer dan media penuh warna (Hernawati \& Uny, 2012). Penelitian yang telah dilakukan membuktikan bahwa penggunaan media berbasis edutaiment dapat meningkatkan motivasi dan hasil belajar siswa (Irvanto, 2010).Selain itu, hasil penelitian yang dilakukan pada tahun 2017 bahwa penggunaan media edutainment dengan dipadu dengan model pembelajaran berbasis proyek dapat meningkatkan hasil belajar serta kreativitas siswa(Ardianti dkk, 2017).

Penggunaan media pembelajaran juga memberikan kontribusi yang cukup besar dalam meningkatkan motivasi dan hasil belajar siswa.Dengan menggunakan media pembelajaran berbasis edutaiment yang mengemas media pembelajaran dalam bentuk hiburan yang menarik diharapkan dapat meningkatkan motivasi siswa dalam belajaran.Berdasarkan hasil penelitian yang telah dilakukan pada tahun 2012 menunjukkan bahwa penerapan pembelajaran berbasis edutaiment dapat meningkatkan motivasi dan hasil belajar matematika siswa (Rahmawati dkk, 2015).

Menurut Susanto (Mawaddah, 2016) siswa yang memiliki kemampuan pemahaman konsep matematika jika ia dapat merumuskan strategi penyelesaian, menerapkan strategi hitung secara sederhana, menggunakan simbol untuk mempresentasikan konsep, dan mengubah suatu bentuk ke bentuk lain misalnya pecahan dalam pembelajaran matematika.Menurut Hudoyo bahwa matematika merupakan ide-ide dan konsep-konsep yang abstrak dan tersusun secara hierarki dan penalaranya deduktif. oleh sebab itu perlu dalam belajar matematika agar dapat memahami konsep dengan baik tidak boleh ada ada tahapan konsep yang dilewatkan. Sebaiknya matematika dipelajari secara sistematis dan teratur disesuaikan dengan perkembangan intelektual siswa serta kemampuan prasyarat yang dimilikinya. (Herawati dkk, 2010).

Adapun indikator dari pemahaman konsep menurut Depdiknas yaitu: (menyatakan ulang sebuah konsep, (2) mengklasifikasi objek menuut sifat-sifat tertentu sesuai dengan konsepnya, (3) memberi contoh dan bukan contoh dari suatu konsep, (4) menyajikan konsep dalam berbagai bentuk representasi matematis, (5) mengembangkan syarat pelu atau syarat cukup suatu konsep, (menggunakan dan memamfaatkan serta memilih prosedur atau operasi tertentu, serta (7) mengaplikasikan konsep atau algoritma pada pemecahan masalah.

Menurut David Krec motivasi merupakan suatu drongan untuk memulai tindakan tertentu (Cleopatra,2015). Setiap orang memerlukan motivasi dalam dirinya untuk melakukan seuatu tindakan tertentu. Menurut Mudjiman (Farhan \& Retnawati, 2014) kegiatan pembelajaran akan selalu didahului oleh proses pembuatan keputusan-keputusan untuk melakukan sesuatu atau tidak, apabila memiliki motivasi yang kuat maka ia akan 


\section{Penerapan Pembelajaran Konstruktivis-Novick dengan Media Edutainment terhadap Motivasi dan Pemahaman Konsep Siswa}

melakukan kegiatan belajar. Sebaliknya, apabila tidak memiliki motivasi yang cukup kuat maka ia tidak akan melakukan kegiatan belajar. Adapun indikator seseorang memiliki motivasi yaitu (1) adanya hasrat dan keinginan untuk melakukan kegiatan, (2) adanya dorongan dan kebutuhan melakukan kegiatan, (3) adanya harapan dan cita-cita, (4) penghargaan dan penghormatan atas diri, (5) adanya lingkungan yang baik, (6) dan adanya kegiatan yang menarik.

Oleh sebab itu dengan melaksanakan pembelajaran yang memadukan model konstruktivis novick dengan media pembelajaran berbasis edutaimnet diharapkan akan menciptakan situasi pembelajaran matematika yang menyenangkan serta melatih siswa mengkonstruksi pengetahuan sehingga materi matematika tersimpan jangka panjang dalam pikiran siswa sehingga akan berdampak pada peningkatan hasil belajar matematika siswa.

\section{METODE}

Penelitian ini dikategorikan ke dalam penelitian eksperimen, yaitu penelitian eksperimen semu (quasi experimental design). Maksud dari penelitian ini untuk mengetahui ada atau tidak ada pengaruh penerapan model pembelajaran konstruktivis novick dengan media berbasis edutaiment terhadap kemampuan pemahaman konsep siswa.

Penelitian ini dilaksanakan di SMA Negeri 1 Wonomulyo Kabupaten Polewali Mandar, yang dilaksanakan pada tahun pelajaran 2018-2019.Populasi dalam penelitian ini adalah siswa kelas X MIPA SMA Negeri 1 Wonomulyo. Pada penelitian ini peneliti akan melakukan random sampling atau teknik acak untuk menentukan sampel penelitian.Adapunsdampel yang digunakan dalam penelitian ini yaitu kelas X MIPA 1 sebagai kelas eksperimen dan kelas X MIPA 3 sebagai kela kontrol.

Data tentang motivasi siswa diperoleh dengan menggunakan angket motivasi siswa yang diberikan pada kelas eksperimen dan kelas kontrol setelah pembelajaran dilaksanakan. sedangkan data tentang kemampuan pemahaman konsep siswa diperoleh dengan menggunakan tes pemahaman konsep yang diberikan kepada siswa setelah pembelajaran dilaksanakan pada kelas eksperimen dan kelas kontrol. Instrumen yang digunakan dalam penelitian ini yaitu tes pemahaman konsep siswa dan angket motivasi belajar siswa yang diberikan kepada kelas eksperimen dan kelas kontrol setelah penerapan pemebelajaran.

Analisis data yang dilakukan dalam penelitian ini yakni dengan menggunakan uji independet sample t-test yaitu untuk menguji perbandingan antara skor rata-rata kemampuan pemahaman konsep dan motivasi belajar matematika siswa antara kelas kontrol dan kelas eksperimen. Namun sebelum dilaksanakan uji hipotesis, dilaksanakan uji prasyarat terlebih dahulu yakni uji normalitas dan uji homogenitas data yang kemudian akan dilanjutkan dengan uji hipotesis. 


\section{HASIL DAN PEMBAHASAN}

Pemahaman konsep siswa pada kelas eksperimen diperoleh rata-rata sebesar 88,37 sedangkan rata-rata pemahaman konsep siswa pada kelas kontrol sebesar 82,57. Berdasarkan hal tersebut dapat dilihat bahwa rata-rata pemahaman konsep siswa yang diajar dengan menggunakan model konstruktivis novick dengan media edutainment lebih besar dibandingkan rata-rata pemahaman konsep matematika siswa yang diajar tanpa menggunakan model konstriktivis novick dengan media edutainment.

Motivasi siswa pada kelas eksperimen diperoleh rata-rata sebesar 83,79 sedangkan rata-rata motivasi belajar siswa pada kelas kontrol sebesar 81,33. Berdasarkan hal tersebut dapat dilihat bahwa rata-rata motivasi siswa yang diajar dengan menggunakan model konstruktivis novick dengan media edutainment lebih besar dibandingkan rata-rata motivasi siswa yang diajar tanpa menggunakan model konstriktivis novick dengan media edutainment. Untuk dapat melaksanakan uji hipotesis dibutuhkan terlebih dahulu melakukan uji normalitas dan uji homogenitas terhadap data skor pemahaman konsep dan motivasi belajar siswa.

Hasil uji normalitas kolmogorov smirnov data pemahaman konsep untuk kelas eksperimen diperoleh sig sebesar $0,110>0,05$, hal ini menunjukkan bahwa data pemahaman konsep kelas eksperimen berdistribusi normal. Sedangan pada kelas kontrol diperoleh data pemahaman konsep siswa sebesar signifikansi 0,134>0,05, hal ini menunjukkan bahwa data pemehaman konsep siswa untuk kelas kontrol juga berdistribusi normal. Data mengenai normalitas pemahaan konsep siswa pada kelas eksperimen dan kelas kontrol disajikan pada Gambar 1 berikut:
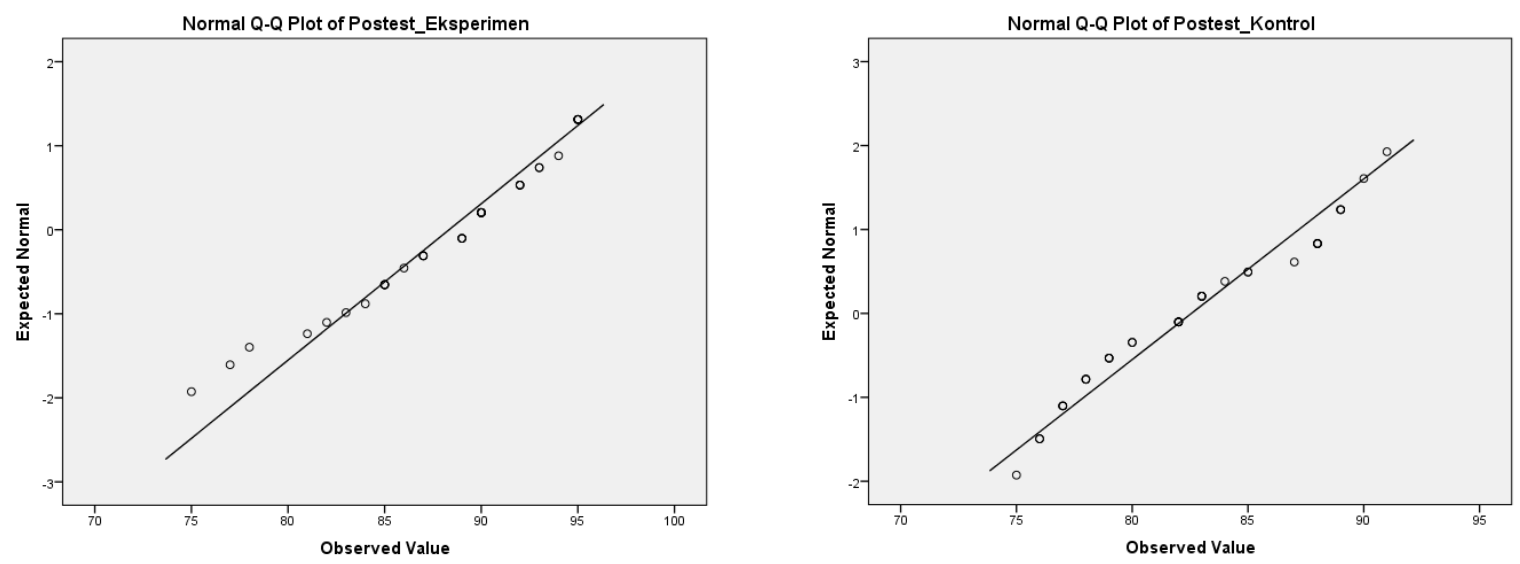

Gambar 1. Normalitas Pemahaman Konsep Kelas Eksperimen dan Kelas Kontrol

Hasil uji normalitas kolmogorov smirnov data motivasi belajar siswa untuk kelas eksperimen diperoleh sig sebesar 0,07 > 0,05, hal ini menunjukkan bahwa data motivasi siswa kelas eksperimen berdistribusi normal. Sedangan pada kelas kontrol diperoleh data 
motivasi belajar siswa signifikansi sebesar 0,200 >0,05, hal ini menunjukkan bahwa data motivasi belajar untuk kelas kontrol juga berdistribusi normal. Data mengenai normalitas motivasi belajar siswa pada kelas eksperimen dan kelas kontrol disajikan pada Gambar 2 berikut:
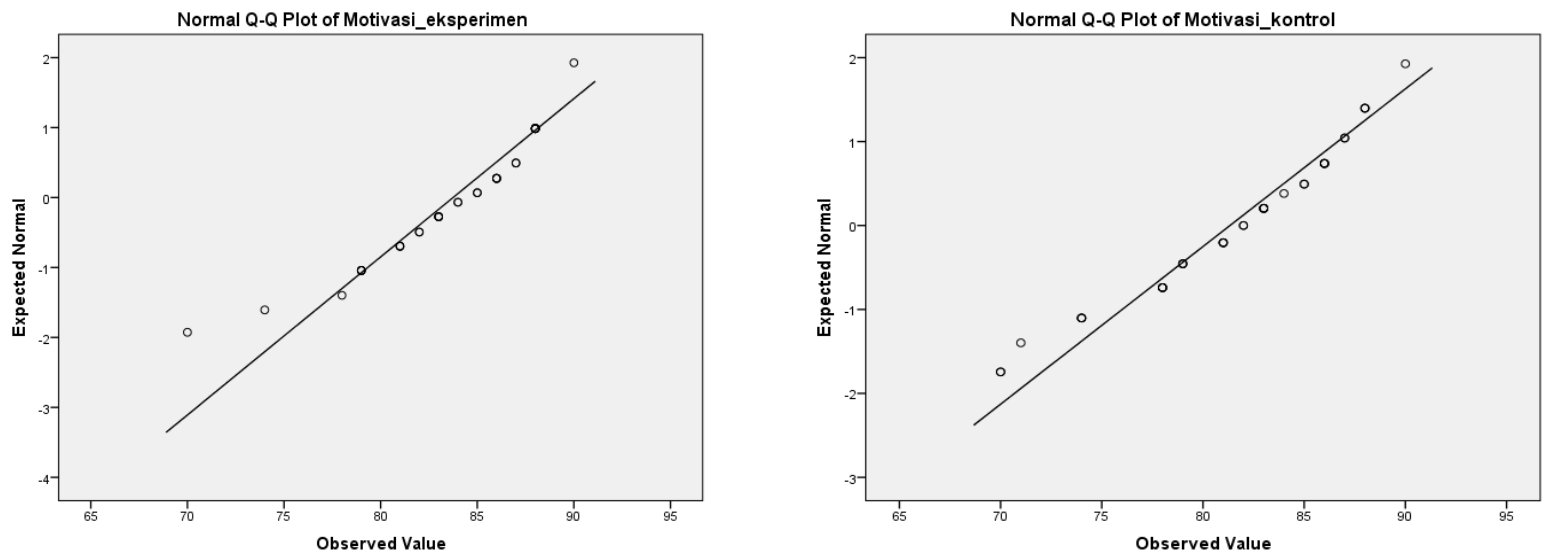

Gambar 2. Normalitas Data Motivasi Siswa Pada Kelas Eksperimen dan Kelas Kontrol

Berdasarkan hasil tes homogenitas dengan menggunakan levene statistic data pemahaman konsep siswa diperoleh sig. 0,662 > 0,05 sehingga dapat disimpulkan bahwa data pemahaman konsep siswa homogen. Sedangkan untuk data motivasi siswa diperoleh sig. 0,197>0,05. Hal ini menunjukkan bahwa data motivasi belajar siswa homogen antara kelas eksperimen dan kelas kontrol.

Karena uji prasyarat data pemahaman konsep dan data motivasi siswa telah terpenuhi yakni berdistribusi normal dan homogen, maka dapat dilanjut pada tahap pengujian hipotesis. pengujian hipotesis yang dilakukan dalam penelitian ini yaitu dengan menggunakan uji independent sample t-test. Hasil analisis data tentang pemahaman konsep siswa disajikan pada Tabel 2 berikut:

Tabel 2. Hasil Uji Hipotesis Data Pemehaman Konsep Siswa

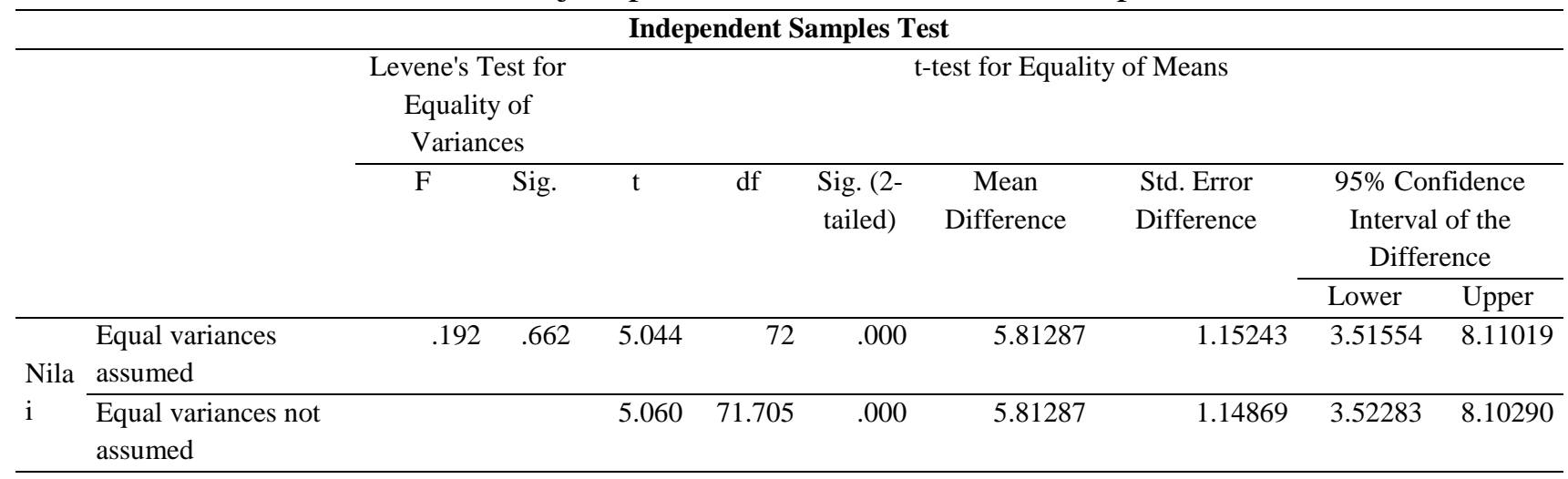

Sumber: Hasil olahan data tahun 2019 
Dari tabel di atas diperoleh bahwa hasil pengujian hipotesis data pemahaman konsep siswa diperoleh sig. $0.000<0,05$. Hal ini menunjukkan bahwa rata-rata pemehaman konsep siswa pada kelas eksperimen lebih besar daripada rata-rata pemahaman konsep siswa pada kelas kontrol. Sedangkan untuk data motivasi siswa diperoleh hasil pengujian hipotesis sebagai berikut:

Tabel 3. Hasil Pengujian Hipotesis Data Motivasi Siswa

\begin{tabular}{|c|c|c|c|c|c|c|c|c|c|}
\hline \multicolumn{10}{|c|}{ Independent Samples Test } \\
\hline & & \multirow{2}{*}{$\begin{array}{c}\text { Levene's Test for } \\
\text { Equality of } \\
\text { Variances }\end{array}$} & \multirow{2}{*}{\multicolumn{7}{|c|}{ t-test for Equality of Means }} \\
\hline & & & & & & & & & \\
\hline & & \multirow[t]{2}{*}{$\mathrm{F}$} & \multirow[t]{2}{*}{$\mathrm{t}$} & \multirow[t]{2}{*}{ df } & \multirow[t]{2}{*}{$\begin{array}{l}\text { Sig. (2- } \\
\text { tailed) }\end{array}$} & \multirow[t]{2}{*}{$\begin{array}{c}\text { Mean } \\
\text { Difference }\end{array}$} & \multirow[t]{2}{*}{$\begin{array}{l}\text { Std. Error } \\
\text { Difference }\end{array}$} & \multicolumn{2}{|c|}{$\begin{array}{l}\text { 95\% Confidence } \\
\text { Interval of the } \\
\text { Difference }\end{array}$} \\
\hline & & & & & & & & Lower & Upper \\
\hline \multirow[b]{2}{*}{ motivasi } & $\begin{array}{l}\text { Equal } \\
\text { variances } \\
\text { assumed }\end{array}$ & $1.696 \quad .197$ & 2.185 & 72 & .032 & 2.45614 & 1.12424 & .21500 & 4.69728 \\
\hline & $\begin{array}{l}\text { Equal } \\
\text { variances } \\
\text { not } \\
\text { assumed }\end{array}$ & & 2.172 & 67.451 & .033 & 2.45614 & 1.13061 & .19971 & 4.71257 \\
\hline
\end{tabular}

Sumber: Hasil olahan data tahun 2019

Dari tabel 3 di atas, diperoleh baha hasil pengujian hipotesis data motivasi diperoleh sig. $0,032<0,05$, hal ini menunjukkan bahwa rata-rata motivasi belajar siswa pada kelas eksperimen lebih besar dibandingkan rata-rata motivasi siswa pada kelas kontrol.

Berdasarkan uji hipotesis, maka dapat disimpulkan bahwa rata-rata pemahaman konsep dan motivasi siswa pada kelas eksperimen lebih besar daripada rata-rata pemahaman konsep dan motivasi siswa pada kelas kontrol. Dengan kata lain bahwa penerapan model konstruktivis novick dengan media edutainment berpengaruh terhadap pemahaman konsep dan motivasi belajar matematika siswa. Hal ini sejalan dengan penelitian yang telah dilakukan oleh Marlina (2011) yang menyatakan bahwa pembelajaran matematika pada pokok bahasan relasi dan fungsi dengan menggunakan model pembelajaran konstruktivisme tipe novick berpengaruh secara signifikan terhadap kemampuan pemahaman konsep matematik siswa. Selain itu, penelitian yang telah dilakukan oleh Astuti (2012) diperoleh kesimpulan bahwa melalui metode pembelajaran edutainment dapat meningkatkan motivasi dan hasil belajar matematika siswa.

Penerapan pembelajaran dengan menggunakan model konstruktivis novick memberikan kesempatan kepada siswa untuk membangun sendriri konsep yang dimilikinya, melakukan percobaan dan membuktikan sendiri mengenai konsep yang dipikirkannya sehingga dapat menemukan konsep yang benar sesuai dengan hasil pembuktian dan percobaan yang telah dilakukan. Selain itu, dengan menggunakan media edutainment dapat membuat suasana yang menyenangkan dalam proses pembelajaran 
matematika. Sehingga dengan memadukan antara model pembelajaran konstruktivis novick dengan media edutainment dapat meningkatkan kemampuan pemahaman konsep matematika siswa, serta dapat pula meningkatkan motivasi siswa dalam belajar matematika.

\section{KESIMPULAN}

Hasil analisis data menunjukan bahwa rata-rata kemampuan pemahaman konsep matematika siswa pada kelas eksperimen sebesar 88,37 sedangkan rata-rata pemahaman konsep siswa pada kelas kontrol sebesar 82,57. Selain itu, motivasi siswa pada kelas eksperimen diperoleh rata-rata sebesar 83,79 sedangkan rata-rata motivasi belajar siswa pada kelas kontrol sebesar 81,33. Berdasarkan uji hipotesis yang telah dilakukan diperoleh bahwa skor rata-rata kemampuan pemahaman konsep siswa pada kelas eksperimen lebih besar daripada skor rata-rata pemahaman konsep siswa pada kelas kontrol, serta skor ratarata motivasi siswa pada kelas eksperimen lebih besar daripada skor rata-rata motivasi siswa pada kelas kontrol. Dengan demikian dapat disimpulkan bahwa penerapan model pembelajaran konstruktivis novick dengan media edutainment berpengaruh terhadap pemahaman konsep dan motivasi belajar matematika siswa.

\section{DAFTAR PUSTAKA}

Andani, M., \& Herawati, S., 2013.Pengembangan Perangkat Pembelajaran Matematika Interaktif Berbasis Edutaiment pada Materi Pokok Peluang Untuk Siswa Kelas IX SMP. Abcstract of Ungraduate, Faculty of Education, Bung Hatta University,2(1).

Ardianti, S.D., Pratiwi, I.A., \& Kanzunnudin, M. 2017. "Implementasi Project Based Learning (PjBL) Berpendekatan Science Edutainment Terhadap Kreativitas Peserta Didik." Refleksi Edukatika,7(2).

Astuti, S.D. (2012). Upaya Peningkatan Motivasi dan Hasil Blejar Matematika Siswa Melalui Metode Pembelajaran Edutainment (Education Entertainment) Siswa Kelas IV SD Negeri 2 Karangnongko Boyolali Tahun Ajaran 2011/2012 (Doctoral Dissertation, Universitas Muhammadiyah Surakarta).

Farhan, M., \& Retnawati H. 2014. Keefektifan PBL dan IBL dari Prestasi Belajar, Kemampuan Representasi Matematis, dan Motivasi Beljaar. Jurnal Riset Pendidikan Matematika. 1(2), 227-240.

Herawati, O.D.P., Siroj, R.A., \& Barir, M.D., (2010). Pengaruh Pembelajaran Problem Posing Terhadap Kemampuan Pemahaman Konsep Matematika Siswa Kelas XI 
IPA SMA Negeri 6 Palembang. Jurnal Pendidikan Matematika, 4(1), 70-80.

Hernawati, K., \& UNY, J. 2012. Pemanfaatan Sumber Belajar Internet Berbasis Edutaiment dalam Pembelajaran Matematika Siswa Sekolah Dasar.Prosiding Seminar NasionalMatematika.

Irvanto, Z.Y. 2010. Penerapan Model Pembelajaran Edutaiment Berdasarkan Quantum Teaching untuk Meningkatkan Motivasi dan Hasil Belajar Biologi Siswa Kelas VIII Pada Materi Sistem dalam Kehidupan Tumbuhan di SMp Negeri 13Malang

Marlina, R. (2014). Pengaruh Model Pembelajaran Konstruktivisme Tipe Novik Terhadap Kemampuan Pemahaman Konsep Relasi dan Fungsi Pada Siswa SMP (Bachelor's thesis, FITK UIN Syarif Hidayatullah Jakarta).

Masruroh, R.D., Karyanto, P., \& Indrowati, M., 2014.Studi Komparasi Pemahaman Konsep Sistem Pernapasan Manuisa Melalui Penerapan Pembelajaran Konstruktivisme Tipe Novick Dipadu Concept Map dan Ceramah Bervariasi.Bioedukasi,7(1).

Mawaddah, S., \& Maryanti, R. (2016). Kemampuan Pemahaman Konsep Matematis Siswa SMP dalam Pembelajaran Menggunakan Model Penemuan Terbimbing (Discovery Learning). EDU-MAT, 4(1).

Prayitno, B.A., \& Sugiharto, B. 2017.Komparasi Model Pembelajaran KonstrukruktivisMetakognitif dan Konstruktivis-Novick Taerhadap Berpikir Kritis Ditinjau dari Kemampuan Akademik.Inferensi,11(1).

Rahmawati, Y., Baskoro A.P., \& Indrowati, M. 2015. Comparison Studi Of Students Misconception Level in Biology Learning Trough Constructivism Tipe Novick and Construktivism-Colaborativ Learning Method. Pendidikan Biologi,7(3).

Sudjana, Nana. 2008. Pembinaan dan Pengembangan Kurikulum di Sekolah.Bandung: Sinar BaruAlgensindo

Sulaiman, N. 2013.Efektivitas Model Pembelajaran Novick dalam Pembelajaran Kimia Kelas XII IA2 SMAN 1 Donri-Donri (Studi Pada Materi Pokok Gugus Fungsi). Chemica, 13(2),67-73.

Susilana, R., Si, M., \& Riyana, C. 2009. Media Pembelajaran: Hakikat, Pengembangan, 
Penerapan Pembelajaran Konstruktivis-Novick dengan Media Edutainment terhadap Motivasi dan Pemahaman Konsep Siswa

Pemanfaatan, dan Penilaian. CV.Wacana Prima.

Triyanto, E., Anitah, S., Suryani, N. 2013. Peran Kepemimpinan Kepaka Sekolah dalam Pemanfaatan Media Pembelajaran Sebagai Upaya Peningkatan Kualitas Proses Pembelajaran. Jurnal Teknologi Pendidikan., 1(2), 226-238. 